\title{
STRONG CONVERGENCE OF SOME ALGORITHMS FOR $\lambda$-STRICT PSEUDO-CONTRACTIONS IN HILBERT SPACE
}

\author{
YONGHONG YAO, YEONG-CHENG LIOU and GIUSEPPE MARINO ${ }^{\bowtie}$
}

\author{
(Received 15 April 2011)
}

Abstract

Two algorithms have been constructed for finding the minimum-norm fixed point of a $\lambda$-strict pseudocontraction $T$ in Hilbert space. It is shown that the proposed algorithms strongly converge to the minimum-norm fixed point of $T$.

2010 Mathematics subject classification: primary 47H05; secondary 47H10, 47H17.

Keywords and phrases: $\lambda$-strictly pseudo-contractive mapping, fixed point, algorithm, Hilbert space.

\section{Introduction}

Let $C$ be a nonempty closed convex subset of a real Hilbert space $H$. Recall that a mapping $T: C \rightarrow C$ is said to be strictly pseudo-contractive if there exists a constant $0 \leq \lambda<1$ such that

$$
\|T x-T y\|^{2} \leq\|x-y\|^{2}+\lambda\|(I-T) x-(I-T) y\|^{2}, \quad \forall x, y \in C .
$$

In such a case we also say that $T$ is a $\lambda$-strictly pseudo-contractive mapping. It is clear that, in a real Hilbert space $H,(1.1)$ is equivalent to

$$
\langle T x-T y, x-y\rangle \leq\|x-y\|^{2}-\frac{1-\lambda}{2}\|(I-T) x-(I-T) y\|^{2}, \quad \forall x, y \in C .
$$

We use $\operatorname{Fix}(T)$ to denote the set of fixed points of $T$.

It is clear that the class of strictly pseudo-contractive mappings strictly includes the class of nonexpansive mappings, which are mappings $T$ on $C$ such that

$$
\|T x-T y\| \leq\|x-y\|, \quad \forall x, y \in C .
$$

Iterative methods for nonexpansive mappings have been extensively investigated in the literature; see $[1,8,9,16,19,23,25,33,35,37]$ and the references therein. Related

The first author was supported in part by the Colleges and Universities Science and Technology Development Foundation (20091003) of Tianjin, NSFC 11071279 and NSFC 71161001-G0105. The second author was supported in part by NSC 100-2221-E-230-012.

(C) 2012 Australian Mathematical Publishing Association Inc. 0004-9727/2012 \$16.00 
work can be found in $[2-7,10-15,17,18,20-22,24,26-32,34,36]$. However, iterative methods for strictly pseudo-contractive mappings are far less developed than those for nonexpansive mappings, although Browder and Petryshyn [2] initiated their work in 1967. Strictly pseudo-contractive mappings have more powerful applications than nonexpansive mappings in solving inverse problems (see Scherzer [21]), so it is of interest to develop algorithms for strictly pseudo-contractive mappings.

On the other hand, in many problems, it is required to find a solution with minimum norm. In an abstract way, we may formulate such problems as finding a point $x^{\dagger}$ with the property

$$
x^{\dagger} \in C \quad \text { and } \quad\left\|x^{\dagger}\right\|^{2}=\min _{x \in C}\|x\|^{2},
$$

where $C$ is a nonempty closed convex subset of a real Hilbert space $H$. In other words, $x^{\dagger}$ is the (nearest point or metric) projection of the origin onto $C$,

$$
x^{\dagger}=P_{C}(0),
$$

where $P_{C}$ is the metric (or nearest point) projection from $H$ onto $C$. A typical example is the least-squares solution to the constrained linear inverse problem

$$
\left\{\begin{array}{l}
A x=b, \\
x \in C,
\end{array}\right.
$$

where $A$ is a bounded linear operator from $H$ to another real Hilbert space $H_{1}$ and $b$ is a given point in $H_{1}$. Related work for finding the minimum-norm solution (or fixed point) has been considered by some authors; see [7, 11, 30-32, 34].

In the present paper, two algorithms have been constructed for finding the minimum-norm fixed point of a $\lambda$-strict pseudo-contraction $T$ in Hilbert space. It is shown that the proposed algorithms strongly converge to the minimum-norm fixed point of $T$.

\section{Preliminaries}

Let $C$ be a nonempty closed convex subset of $H$. For every point $x \in H$, there exists a unique nearest point in $C$, denoted by $P_{C} x$, such that

$$
\left\|x-P_{C} x\right\| \leq\|x-y\|, \quad \forall y \in C .
$$

The mapping $P_{C}$ is called the metric projection of $H$ onto $C$. It is well known that $P_{C}$ is a nonexpansive mapping and is characterised by the following property:

$$
\left\langle x-P_{C} x, y-P_{C} x\right\rangle \leq 0, \quad \forall x \in H, y \in C .
$$

In order to prove our main results, we need the following well-known lemmas.

Lemma 2.1. Let $C$ be a nonempty, closed and convex subset of a real Hilbert space $H$. Let $T: C \rightarrow C$ be a $\lambda$-strictly pseudo-contractive mapping. Then $I-T$ is demi-closed at 0 , that is, if $x_{n} \rightarrow x \in C$ and $x_{n}-T x_{n} \rightarrow 0$, then $x=T x$. 
LEMMA 2.2. Assume that $\left\{a_{n}\right\}$ is a sequence of nonnegative real numbers such that $a_{n+1} \leq\left(1-\gamma_{n}\right) a_{n}+\gamma_{n} \delta_{n}, n \geq 0$, where $\left\{\gamma_{n}\right\}$ is a sequence in $(0,1)$ and $\left\{\delta_{n}\right\}$ is a sequence in $\mathbb{R}$ such that:

(i) $\sum_{n=0}^{\infty} \gamma_{n}=\infty$;

(ii) $\limsup _{n \rightarrow \infty} \delta_{n} \leq 0$ or $\sum_{n=0}^{\infty}\left|\delta_{n} \gamma_{n}\right|<\infty$.

Then $\lim _{n \rightarrow \infty} a_{n}=0$.

\section{Main results}

Let $C$ be a nonempty closed convex subset of a real Hilbert space $H$. Let $T: C \rightarrow C$ be a $\lambda$-strict pseudo-contraction. Let $k \in(0,1-\lambda)$ be a constant. For each $t \in(0,1)$, we consider the mapping $T_{t}$ given by

$$
T_{t} x=P_{C}((1-k-t) x+k T x), \quad \forall x \in C .
$$

It is easy to check that $T_{t}: C \rightarrow C$ is a contraction for a small enough $t$. As a matter of fact, from (1.1) and (1.2),

$$
\begin{aligned}
\left\|T_{t} x-T_{t} y\right\|^{2}= & \left\|P_{C}((1-k-t) x+k T x)-P_{C}((1-k-t) y+k T y)\right\|^{2} \\
\leq & \|(1-k-t)(x-y)+k(T x-T y)\|^{2} \\
= & (1-k-t)^{2}\|x-y\|^{2}+k^{2}\|T x-T y\|^{2} \\
& \quad+2(1-k-t) k\langle T x-T y, x-y\rangle \\
\leq & (1-k-t)^{2}\|x-y\|^{2}+k^{2}\left(\|x-y\|^{2}+\lambda\|(I-T) x-(I-T) y\|^{2}\right) \\
& \quad+2(1-k-t) k\left(\|x-y\|^{2}-\frac{1-\lambda}{2}\|(I-T) x-(I-T) y\|^{2}\right) \\
= & \left(\lambda k^{2}-(1-\lambda)(1-k-t) k\right)\|(I-T) x-(I-T) y\|^{2}+(1-t)^{2}\|x-y\|^{2} \\
= & k(k-(1-t)(1-\lambda))\|(I-T) x-(I-T) y\|^{2}+(1-t)^{2}\|x-y\|^{2} .
\end{aligned}
$$

We can choose a small enough $t$ such that $k \leq(1-t)(1-\lambda)$. Then, from (3.1),

$$
\left\|T_{t} x-T_{t} y\right\| \leq(1-t)\|x-y\|, \quad \forall x, y \in C,
$$

which implies that $T_{t}$ is a contraction. Using the Banach contraction principle, there exists a unique fixed point $x_{t}$ of $T_{t}$ in $C$, that is,

$$
x_{t}=P_{C}\left((1-k-t) x_{t}+k T x_{t}\right) .
$$

Theorem 3.1. Suppose that $\operatorname{Fix}(T) \neq \emptyset$. Then, as $t \rightarrow 0$, the net $\left\{x_{t}\right\}$ generated by (3.3) converges strongly to the minimum-norm fixed point of $T$. 
Proof. First, we prove that $\left\{x_{t}\right\}$ is bounded. Take $u \in \operatorname{Fix}(T)$. From (3.3) and (3.2),

$$
\begin{aligned}
\left\|x_{t}-u\right\| & =\left\|P_{C}\left((1-k-t) x_{t}+k T x_{t}\right)-P_{C} u\right\| \\
& \leq\left\|(1-k-t)\left(x_{t}-u\right)+k\left(T x_{t}-u\right)-t u\right\| \\
& \leq(1-t)\left\|x_{t}-u\right\|+t\|u\|,
\end{aligned}
$$

that is, $\left\|x_{t}-u\right\| \leq\|u\|$, which implies that $\left\{x_{t}\right\}$ is bounded and so is $\left\{T x_{t}\right\}$.

From (3.3),

$$
\begin{aligned}
\left\|x_{t}-T x_{t}\right\| & =\left\|P_{C}\left((1-k-t) x_{t}+k T x_{t}\right)-P_{C} T x_{t}\right\| \\
& \leq\left\|(1-k)\left(x_{t}-T x_{t}\right)-t x_{t}\right\| \\
& \leq(1-k)\left\|x_{t}-T x_{t}\right\|+t\left\|x_{t}\right\| .
\end{aligned}
$$

It follows that

$$
\left\|x_{t}-T x_{t}\right\| \leq \frac{t}{k}\left\|x_{t}\right\| \rightarrow 0 .
$$

Next we show that $\left\{x_{t}\right\}$ is relatively norm-compact as $t \rightarrow 0$. Assume that $\left\{t_{n}\right\} \subset(0,1)$ is such that $t_{n} \rightarrow 0$ as $n \rightarrow \infty$. Put $x_{n}:=x_{t_{n}}$. From (3.4),

$$
\left\|x_{n}-T x_{n}\right\| \rightarrow 0
$$

Setting $y_{t}=(1-k-t) x_{t}+k T x_{t}$, we then have $x_{t}=P_{C} y_{t}$, and, for any $u \in \operatorname{Fix}(T)$,

$$
\begin{aligned}
x_{t}-u & =x_{t}-y_{t}+y_{t}-u \\
& =x_{t}-y_{t}+(1-k-t)\left(x_{t}-u\right)+k\left(T x_{t}-u\right)-t u .
\end{aligned}
$$

Using the property (2.1) of the metric projection,

$$
\left\langle x_{t}-y_{t}, x_{t}-u\right\rangle \leq 0 \text {. }
$$

Combining (3.6) and (3.7),

$$
\begin{aligned}
\left\|x_{t}-u\right\|^{2} & =\left\langle x_{t}-y_{t}, x_{t}-u\right\rangle+\left\langle(1-k-t)\left(x_{t}-u\right)+k\left(T x_{t}-u\right), x_{t}-u\right\rangle-t\left\langle u, x_{t}-u\right\rangle \\
& \leq\left\|(1-k-t)\left(x_{t}-u\right)+k\left(T x_{t}-u\right)\right\|\left\|x_{t}-u\right\|-t\left\langle u, x_{t}-u\right\rangle \\
& \leq(1-t)\left\|x_{t}-u\right\|^{2}-t\left\langle u, x_{t}-u\right\rangle .
\end{aligned}
$$

Hence, $\left\|x_{t}-u\right\|^{2} \leq\left\langle u, u-x_{t}\right\rangle$. In particular,

$$
\left\|x_{n}-u\right\|^{2} \leq\left\langle u, u-x_{n}\right\rangle, \quad u \in \operatorname{Fix}(T) .
$$

Since $\left\{x_{n}\right\}$ is bounded we may assume, without loss of generality, that $\left\{x_{n}\right\}$ converges weakly to a point $x^{*} \in C$. Noting (3.5), we can use Lemma 2.1 to get $x^{*} \in \operatorname{Fix}(T)$. Therefore we can substitute $x^{*}$ for $u$ in (3.8) to get

$$
\left\|x_{n}-x^{*}\right\|^{2} \leq\left\langle x^{*}, x^{*}-x_{n}\right\rangle .
$$


Consequently, the weak convergence of $\left\{x_{n}\right\}$ to $x^{*}$ actually implies that $x_{n} \rightarrow x^{*}$ strongly. This proves the relative norm-compactness of the net $\left\{x_{t}\right\}$ as $t \rightarrow 0$.

To show that the entire net $\left\{x_{t}\right\}$ converges to $x^{*}$, assume that $x_{s_{n}} \rightarrow \tilde{x} \in \operatorname{Fix}(T)$, where $s_{n} \rightarrow 0$. In (3.8), we take $u=\tilde{x}$ to get

$$
\left\|x^{*}-\tilde{x}\right\|^{2} \leq\left\langle\tilde{x}, \tilde{x}-x^{*}\right\rangle .
$$

Interchange $x^{*}$ and $\tilde{x}$ to obtain

$$
\left\|\tilde{x}-x^{*}\right\|^{2} \leq\left\langle x^{*}, x^{*}-\tilde{x}\right\rangle .
$$

Adding (3.9) and (3.10) yields

$$
2\left\|x^{*}-\tilde{x}\right\|^{2} \leq\left\|x^{*}-\tilde{x}\right\|^{2},
$$

which implies that $\tilde{x}=x^{*}$.

Finally, we return to (3.8) and take the limit as $n \rightarrow \infty$ to get

$$
\left\|x^{*}-u\right\|^{2} \leq\left\langle u, u-x^{*}\right\rangle, \quad u \in \operatorname{Fix}(T) .
$$

Equivalently,

$$
\left\|x^{*}\right\|^{2} \leq\left\langle x^{*}, u\right\rangle, \quad u \in \operatorname{Fix}(T) .
$$

This clearly implies that

$$
\left\|x^{*}\right\| \leq\|u\|, \quad u \in \operatorname{Fix}(T) .
$$

Therefore, $x^{*}$ is a minimum-norm fixed point of $T$. This completes the proof.

Corollary 3.2. Suppose that $\operatorname{Fix}(T) \neq \emptyset$ and the origin 0 belongs to $C$. Then, as $t \rightarrow 0+$, the net $\left\{x_{t}\right\}$ generated by the algorithm

$$
x_{t}=(1-k-t) x_{t}+k T x_{t}
$$

converges strongly to the minimum-norm fixed point of $T$.

Now we propose the following iterative algorithm which is the discretisation of the implicit method (3.3). For given $x_{0} \in C$, chosen arbitrarily, let the sequence $\left\{x_{n}\right\}$ be generated iteratively by

$$
x_{n+1}=P_{C}\left(\left(1-k-\alpha_{n}\right) x_{n}+k T x_{n}\right), \quad n \geq 0,
$$

where $\left\{\alpha_{n}\right\}$ is a real sequence in $(0,1)$.

Theorem 3.3. Suppose that $\operatorname{Fix}(T) \neq \emptyset$ and the following conditions are satisfied:

(i) $\lim _{n \rightarrow \infty} \alpha_{n}=0$ and $\sum_{n=0}^{\infty} \alpha_{n}=\infty$;

(ii) $\lim _{n \rightarrow \infty}\left(\alpha_{n} / \alpha_{n+1}\right)=1$.

Then the sequence $\left\{x_{n}\right\}$ generated by (3.11) strongly converges to the minimum-norm fixed point $x^{*}$ of $T$. 
Proof. First, we prove that the sequence $\left\{x_{n}\right\}$ is bounded. Take $x^{*} \in \operatorname{Fix}(T)$. From (3.11),

$$
\begin{aligned}
\left\|x_{n+1}-x^{*}\right\| & =\left\|P_{C}\left(\left(1-k-\alpha_{n}\right) x_{n}+k T x_{n}\right)-x^{*}\right\| \\
& \leq\left\|\left(1-k-\alpha_{n}\right)\left(x_{n}-x^{*}\right)+k\left(T x_{n}-x^{*}\right)\right\|+\alpha_{n}\left\|x^{*}\right\| .
\end{aligned}
$$

From (3.2), we note that

$$
\left\|\left(1-k-\alpha_{n}\right)\left(x_{n}-x^{*}\right)+k\left(T x_{n}-x^{*}\right)\right\| \leq\left(1-\alpha_{n}\right)\left\|x_{n}-x^{*}\right\| .
$$

It follows from (3.12) and (3.13) that

$$
\begin{aligned}
\left\|x_{n+1}-x^{*}\right\| & \leq\left(1-\alpha_{n}\right)\left\|x_{n}-x^{*}\right\|+\alpha_{n}\left\|x^{*}\right\| \\
& \leq \max \left\{\left\|x_{n}-x^{*}\right\|,\left\|x^{*}\right\|\right\} \\
& \leq \max \left\{\left\|x_{0}-x^{*}\right\|,\left\|x^{*}\right\|\right\} .
\end{aligned}
$$

Hence, $\left\{x_{n}\right\}$ is bounded and so is $\left\{T x_{n}\right\}$.

We now estimate $\left\|x_{n+1}-x_{n}\right\|$. From (3.11),

$$
\begin{aligned}
\left\|x_{n+1}-x_{n}\right\|= & \| P_{C}\left(\left(1-k-\alpha_{n}\right) x_{n}+k T x_{n}\right) \\
& \quad-P_{C}\left(\left(1-k-\alpha_{n-1}\right) x_{n-1}+k T x_{n-1}\right) \| \\
\leq & \|\left(1-k-\alpha_{n}\right)\left(x_{n}-x_{n-1}\right)+k\left(T x_{n}-T x_{n-1}\right) \\
& \quad+\left(\alpha_{n-1}-\alpha_{n}\right) x_{n-1} \| \\
\leq & \left\|\left(1-k-\alpha_{n}\right)\left(x_{n}-x_{n-1}\right)+k\left(T x_{n}-T x_{n-1}\right)\right\| \\
& \quad+\mid \alpha_{n-1}-\alpha_{n}\left\|x_{n-1}\right\| \\
\leq & \left(1-\alpha_{n}\right)\left\|x_{n}-x_{n-1}\right\|+\left|\alpha_{n-1}-\alpha_{n}\right| M,
\end{aligned}
$$

where $M>0$ is a constant such that $\sup _{n}\left\{\left\|x_{n}\right\|\right\} \leq M$. Using Lemma 2.2 with (3.14), we conclude that

$$
\lim _{n \rightarrow \infty}\left\|x_{n+1}-x_{n}\right\|=0
$$

We observe that

$$
\begin{aligned}
\left\|x_{n}-T x_{n}\right\| & \leq\left\|x_{n}-x_{n+1}\right\|+\left\|x_{n+1}-T x_{n}\right\| \\
& \leq\left\|x_{n}-x_{n+1}\right\|+(1-k)\left\|x_{n}-T x_{n}\right\|+\alpha_{n}\left\|x_{n}\right\|,
\end{aligned}
$$

that is,

$$
\left\|x_{n}-T x_{n}\right\| \leq \frac{1}{k}\left\{\left\|x_{n+1}-x_{n}\right\|+\alpha_{n} M\right\} \rightarrow 0 .
$$

Let the net $\left\{x_{t}\right\}$ be defined by (3.3). By Theorem 3.1, $x_{t} \rightarrow x^{*}$ as $t \rightarrow 0$. Next we prove that $\lim _{\sup _{n \rightarrow \infty}}\left\langle x^{*}, x^{*}-x_{n}\right\rangle \leq 0$. 
Set $y_{t}=(1-k-t) x_{t}+k T x_{t}$. It follows that

$$
\begin{aligned}
\left\|x_{t}-x_{n}\right\|^{2}= & \left\langle x_{t}-y_{t}, x_{t}-x_{n}\right\rangle+\left\langle y_{t}-x_{n}, x_{t}-x_{n}\right\rangle \\
\leq & \left\langle y_{t}-x_{n}, x_{t}-x_{n}\right\rangle \\
= & \left\langle(1-k-t)\left(x_{t}-x_{n}\right)+k\left(T x_{t}-T x_{n}\right), x_{t}-x_{n}\right\rangle \\
& \quad+k\left\langle T x_{n}-x_{n}, x_{t}-x_{n}\right\rangle-t\left\langle x_{n}, x_{t}-x_{n}\right\rangle \\
\leq & (1-t)\left\|x_{t}-x_{n}\right\|^{2}+k\left\|T x_{n}-x_{n}\right\|\left\|x_{t}-x_{n}\right\| \\
& \quad-t\left\langle x_{n}-x_{t}, x_{t}-x_{n}\right\rangle-t\left\langle x_{t}, x_{t}-x_{n}\right\rangle \\
= & \left\|x_{t}-x_{n}\right\|^{2}+k\left\|T x_{n}-x_{n}\right\|\left\|x_{t}-x_{n}\right\|-t\left\langle x_{t}, x_{t}-x_{n}\right\rangle,
\end{aligned}
$$

and hence that

Therefore,

$$
\left\langle x_{t}, x_{t}-x_{n}\right\rangle \leq \frac{k}{t}\left\|T x_{n}-x_{n}\right\|\left\|x_{t}-x_{n}\right\| .
$$

$$
\limsup _{t \rightarrow 0} \limsup _{n \rightarrow \infty}\left\langle x_{t}, x_{t}-x_{n}\right\rangle \leq 0 .
$$

Note that the two limits lim $\sup _{t \rightarrow 0}$ and lim $\sup _{n \rightarrow \infty}$ are interchangeable. In fact,

$$
\begin{aligned}
\left\langle x^{*}, x^{*}-x_{n}\right\rangle & =\left\langle x^{*}, x^{*}-x_{t}\right\rangle+\left\langle x^{*}-x_{t}, x_{t}-x_{n}\right\rangle+\left\langle x_{t}, x_{t}-x_{n}\right\rangle \\
& \leq\left\langle x^{*}, x^{*}-x_{t}\right\rangle+\left\|x^{*}-x_{t}\right\|\left\|x_{t}-x_{n}\right\|+\left\langle x_{t}, x_{t}-x_{n}\right\rangle \\
& \leq\left\langle x^{*}, x^{*}-x_{t}\right\rangle+\left\|x^{*}-x_{t}\right\| M+\left\langle x_{t}, x_{t}-x_{n}\right\rangle .
\end{aligned}
$$

This, together with $x_{t} \rightarrow x^{*}$ and (3.15), implies that

$$
\limsup _{n \rightarrow \infty}\left\langle x^{*}, x^{*}-x_{n}\right\rangle \leq 0 \text {. }
$$

Finally, we show that $x_{n} \rightarrow x^{*}$. Set $y_{n}=\left(1-k-\alpha_{n}\right) x_{n}+k T x_{n}$ for all $n \geq 0$. From (3.11),

$$
\begin{aligned}
\left\|x_{n+1}-x^{*}\right\|^{2}= & \left\langle x_{n+1}-y_{n}, x_{n+1}-x^{*}\right\rangle+\left\langle y_{n}-x^{*}, x_{n+1}-x^{*}\right\rangle \\
\leq & \left\langle y_{n}-x^{*}, x_{n+1}-x^{*}\right\rangle \\
= & \left\langle\left(1-k-\alpha_{n}\right)\left(x_{n}-x^{*}\right)+k\left(T x_{n}-x^{*}\right), x_{n+1}-x^{*}\right\rangle \\
& \quad+\alpha_{n}\left\langle x^{*}, x^{*}-x_{n+1}\right\rangle \\
\leq & \left\|\left(1-k-\alpha_{n}\right)\left(x_{n}-x^{*}\right)+k\left(T x_{n}-x^{*}\right)\right\|\left\|x_{n+1}-x^{*}\right\| \\
& \quad+\alpha_{n}\left\langle x^{*}, x^{*}-x_{n+1}\right\rangle \\
\leq & \left(1-\alpha_{n}\right)\left\|x_{n}-x^{*}\right\|\left\|x_{n+1}-x^{*}\right\|+\alpha_{n}\left\langle x^{*}, x^{*}-x_{n+1}\right\rangle \\
\leq & \frac{1-\alpha_{n}}{2}\left(\left\|x_{n}-x^{*}\right\|^{2}+\left\|x_{n+1}-x^{*}\right\|^{2}\right)+\alpha_{n}\left\langle x^{*}, x^{*}-x_{n+1}\right\rangle .
\end{aligned}
$$

It follows that

$$
\left\|x_{n+1}-x^{*}\right\|^{2} \leq\left(1-\alpha_{n}\right)\left\|x_{n}-x^{*}\right\|^{2}+\frac{2 \alpha_{n}}{1+\alpha_{n}}\left\langle x^{*}, x^{*}-x_{n+1}\right\rangle .
$$

We can check that all assumptions of Lemma 2.2 are satisfied. Therefore, $x_{n} \rightarrow x^{*}$. This completes the proof. 
Corollary 3.4. Suppose that $\operatorname{Fix}(T) \neq \emptyset$ and the origin 0 belongs to $C$. Assume that the following conditions are satisfied:

(i) $\lim _{n \rightarrow \infty} \alpha_{n}=0$ and $\sum_{n=0}^{\infty} \alpha_{n}=\infty$;

(ii) $\lim _{n \rightarrow \infty}\left(\alpha_{n} / \alpha_{n+1}\right)=1$.

Then the sequence $\left\{x_{n}\right\}$ generated by the algorithm

$$
x_{n+1}=\left(1-k-\alpha_{n}\right) x_{n}+k T x_{n}, n \geq 0,
$$

converges strongly to the minimum-norm fixed point $x^{*}$ of $T$.

\section{References}

[1] H. Bauschke, 'The approximation of fixed points of compositions of nonexpansive mappings in Hilbert spaces', J. Math. Anal. Appl. 202 (1996), 150-159.

[2] F. E. Browder and W. V. Petryshyn, 'Construction of fixed points of nonlinear mappings in Hilbert spaces', J. Math. Anal. Appl. 20 (1967), 197-228.

[3] L. C. Ceng, P. Cubiotti and J. C. Yao, 'Strong convergence theorems for finitely many nonexpansive mappings and applications', Nonlinear Anal. 67 (2007), 1464-1473.

[4] J. P. Chancelier, 'Iterative schemes for computing fixed points of nonexpansive mappings in Banach spaces', J. Math. Anal. Appl. 353 (2009), 141-153.

[5] S. S. Chang, 'Viscosity approximation methods for a finite family of nonexpansive mappings in Banach spaces', J. Math. Anal. Appl. 323 (2006), 1402-1416.

[6] Y. J. Cho and X. Qin, 'Convergence of a general iterative method for nonexpansive mappings in Hilbert spaces', J. Comput. Appl. Math. 228(1) (2009), 458-465.

[7] Y. L. Cui and X. Liu, 'Notes on Browder's and Halpern's methods for nonexpansive maps', Fixed Point Theory 10(1) (2009), 89-98.

[8] J. S. Jung, 'Iterative approaches to common fixed points of nonexpansive mappings in Banach spaces', J. Math. Anal. Appl. 302 (2005), 509-520.

[9] T. H. Kim and H. K. Xu, 'Strong convergence of modified Mann iterations', Nonlinear Anal. 61 (2005), 51-60.

[10] G. Lewicki and G. Marino, 'On some algorithms in Banach spaces finding fixed points of nonlinear mappings', Nonlinear Anal. 71 (2009), 3964-3972.

[11] X. Liu and Y. Cui, 'Common minimal-norm fixed point of a finite family of nonexpansive mappings', Nonlinear Anal. 73 (2010), 76-83.

[12] G. Lopez, V. Martin and H. K. Xu, 'Perturbation techniques for nonexpansive mappings with applications', Nonlinear Anal. Real World Appl. 10 (2009), 2369-2383.

[13] P. E. Mainge, 'Approximation methods for common fixed points of nonexpansive mappings in Hilbert spaces', J. Math. Anal. Appl. 325 (2007), 469-479.

[14] G. Marino and H. K. Xu, 'Convergence of generalized proximal point algorithms', Commun. Pure Appl. Anal. 3 (2004), 791-808.

[15] G. Marino and H. K. Xu, 'Weak and strong convergence theorems for strict pseudocontractions in Hilbert spaces', J. Math. Anal. Appl. 329 (2007), 336-349.

[16] A. Moudafi, 'Viscosity approximation methods for fixed-point problems', J. Math. Anal. Appl. 241 (2000), 46-55.

[17] A. Petrusel and J. C. Yao, 'Viscosity approximation to common fixed points of families of nonexpansive mappings with generalized contractions mappings', Nonlinear Anal. 69 (2008), $1100-1111$.

[18] S. Plubtieng and R. Wangkeeree, 'Strong convergence of modified Mann iterations for a countable family of nonexpansive mappings', Nonlinear Anal. 70 (2009), 3110-3118.

[19] S. Reich, 'Weak convergence theorems for nonexpansive mappings in Banach spaces', J. Math. Anal. Appl. 67 (1979), 274-276. 
[20] S. Saeidi, 'Iterative algorithms for finding common solutions of variational inequalities and systems of equilibrium problems and fixed points of families and semigroups of nonexpansive mappings', Nonlinear Anal. 70(12) (2009), 4195-4208.

[21] O. Scherzer, 'Convergence criteria of iterative methods based on Landweber iteration for solving nonlinear problems', J. Math. Anal. Appl. 194 (1991), 911-933.

[22] M. Shang, Y. Su and X. Qin, 'Three-step iterations for nonexpansive mappings and inversestrongly monotone mappings', J. Syst. Sci. Complex. 22(2) (2009), 333-344.

[23] N. Shioji and W. Takahashi, 'Strong convergence of approximated sequences for nonexpansive mappings in Banach spaces', Proc. Amer. Math. Soc. 125 (1997), 3641-3645.

[24] M. V. Solodov and B. F. Svaiter, 'Forcing strong convergence of proximal point iterations in a Hilbert space', Math. Program. Ser. A 87 (2000), 189-202.

[25] T. Suzuki, 'Strong convergence of approximated sequences for nonexpansive mappings in Banach spaces', Proc. Amer. Math. Soc. 135 (2007), 99-106.

[26] D. Wu, S. S. Chang and G. X. Yuan, 'Approximation of common fixed points for a family of finite nonexpansive mappings in Banach space', Nonlinear Anal. 63 (2005), 987-999.

[27] H. K. Xu, 'Iterative algorithms for nonlinear operators', J. London Math. Soc. 66 (2002), 240-256.

[28] H. K. Xu, 'Another control condition in an iterative method for nonexpansive mappings', Bull. Aust. Math. Soc. 65 (2002), 109-113.

[29] H. K. Xu, 'Iterative methods for constrained Tikhonov regularization', Comm. Appl. Nonlinear Anal. 10(4) (2003), 49-58.

[30] H. K. Xu, 'Iterative methods for the split feasibility problem in infinite-dimensional Hilbert spaces', Inverse Problems 26 (2010), 105018 (17pp).

[31] Y. Yao, R. Chen and H. K. Xu, 'Schemes for finding minimum-norm solutions of variational inequalities', Nonlinear Anal. 72 (2010), 3447-3456.

[32] Y. Yao and Y. C. Liou, 'An implicit extragradient method for hierarchical variational inequalities', Fixed Point Theory Appl. 2011 (2011), 697248 (11pp).

[33] Y. Yao, Y. C. Liou and R. Chen, 'A general iterative method for an infinite family of nonexpansive mappings', Nonlinear Anal. 69 (2008), 1644-1654.

[34] Y. Yao and H. K. Xu, 'Iterative methods for finding minimum-norm fixed points of nonexpansive mappings with applications', Optimization 60(6) (2011), 645-658.

[35] H. Zegeye and N. Shahzad, 'Viscosity approximation methods for a common fixed point of finite family of nonexpansive mappings', Appl. Math. Comput. 191 (2007), 155-163.

[36] L. C. Zeng, N. C. Wong and J. C. Yao, 'Strong convergence theorems for strictly pseudocontractive mappings of Browder-Petryshyn type', Taiwanese J. Math. 10 (2006), 837-849.

[37] L. C. Zeng and J. C. Yao, 'Implicit iteration scheme with perturbed mapping for common fixed points of a finite family of nonexpansive mappings', Nonlinear Anal. 64 (2006), 2507-2515.

\author{
YONGHONG YAO, Department of Mathematics, \\ Tianjin Polytechnic University, Tianjin 300387, China \\ e-mail: yaoyonghong@yahoo.cn
}

YEONG-CHENG LIOU, Department of Information Management, Cheng Shiu University, Kaohsiung 833, Taiwan e-mail: simplex_liou@ hotmail.com

GIUSEPPE MARINO, Dipartimento di Matematica, Università della Calabria, 87036 Arcavacata di Rende (CS), Italy e-mail: gmarino@unical.it 